\title{
Experimental analysis of laterally loaded nailed timber-to-concrete connections.
}

\section{Jorge M. Branco*}

Assistant research, ISISE, University of Minho, Department of Civil Engineering, 4800-

058 Campus de Azurém, Guimarães, Portugal

* Corresponding author. Tel.: +351 253510 200; fax: +351 253510217 .

E-mail address: jbranco@civil.uminho.pt (Jorge Branco).

\section{Paulo J.S. Cruz}

Professor, ISISE, University of Minho, Department of Civil Engineering, 4800-058

Campus de Azurém, Guimarães, Portugal

\section{Maurizio Piazza}

Professor, University of Trento, Department of Mechanical and Structural Engineering, Via Mesiano 77, 38050 Trento, Italy

\begin{abstract}
This work intends to assess the accuracy of the methodology proposed in the Eurocode 5 for laterally loaded nailed timber-to-concrete connections. First, the adequacy of the methodology proposed by Eurocode 5 for the dowel-type fasteners is analyzed and discussed, using timber elements from Pinus pinaster Ait. Square and round smooth nails have been used, initially on push-out tests of single and double shear dowel-type connections. Later, a similar investigation is carried out on timber-concrete connections, using the same kind of fasteners (nails), in single shear, wood species and experimental procedure. The use and the influence of permanent formwork are also investigated. As a result, comparisons between the values obtained for the load-carrying capacity and the slip modulus using the analysis provided by the Eurocode 5, when existing, and the experimental results are presented.
\end{abstract}

\section{Keywords}

Timber-concrete connections; nails;load-carrying; slip modulus; Eurocode 5. 


\section{Introduction}

In timber structures, joints and connections frequently represent the weakest points. An inadequate design is responsible for many pathologies and their mechanical behaviour, particularly their stiffness, plays a crucial role in stress distribution in the structure.

Timber joints are often less effective than corresponding joints in steel, for instance, due to the relatively low embedding strength and to the low strength of wood in shear and, particularly, in tension perpendicular to grain [1].

Forces between timber members are most often transferred through carpenter joints or gussets joints, either by adhesives (glues) or by laterally loaded dowel-type fasteners (nails, bolts, screws, dowels or nail plates). Nails represent the easiest method to connect timber members. Their simplicity as fasteners, added to the facility of application, are the main advantages. Connecting timber, steel or wood-based panels as side members, nails work primarily in single shear and never in the grain direction where they are submitted to tension. They usually have circular or square cross-section with a diameter of between $2 \mathrm{~mm}$ and $6 \mathrm{~mm}$ and length of between $30 \mathrm{~mm}$ and $200 \mathrm{~mm}$. For years, the use of nails in construction was based in empirical rules. So, the majority of the old design codes did not considered nails or even forbidden them in structural applications [2].

Nowadays, the European Yield Model (EYM) originally proposed by Johansen (1949) [3], that can be found in the Eurocode 5 part 1 [4], is generally accepted for the determination of the lateral load-carrying capacity of dowel-type fasteners, especially for ductile failures. The equations based on this theory predict the load-carrying capacity of a single fastener, per shear plane, loaded perpendicular to his axis, depending on the material properties of the timber and the fasteners and on the geometry of the connection. The deformation behaviour of those connections is based on the slip modulus of a single fastener per shear plane that can be achieved by tests 
according EN 26891:1991 [5], or either calculated using expressions proposed in Eurocode 5.

Other common application of dowel-type fasteners is in the composite timber-concrete slabs. Frequently used in restoration works, especially when load-carrying improvement of old timber slabs is needed, this composite system consists of timber members in the tensile zone, a thin concrete layer in the compression zone connected together by means of fasteners or special connector devices.

Composite timber-concrete systems result not only in the strengthening of the timber floor by adding a concrete slab, but also in improving sound insulation, thermal inertia and fire safety. Compared to traditional solutions, the composite systems result in: lower weight than all-reinforced concrete systems; significantly higher capacity of loadcarrying and higher flexural rigidity than traditional timber floor systems; improved performance as in-plane behaviour; and enhanced vibration control of the floors [6]. The timber-concrete connection, which governs the structural behaviour of such systems, is frequently achieved by nails, screws or steel bars, which can be classified as dowel-type fasteners. In spite of the good results achieved by this technique, no specific analysis method is presented in Eurocode 5 for dowel-type fasteners when used in timber-to-concrete connections. In Eurocode 5 part 2 [7], it is assumed that the slip modulus will be double, compared to similar systems of timber-to-timber connections. The aim of this research is to report the adequacy of the methodology proposed in the Eurocode 5 for laterally loaded nailed connections, and, specially, for the application in composite timber-concrete elements. In the first part, the calculation methodology established by Eurocode 5 part 1 [4] for the timber-to-timber nailed connections is analyzed. After, the same comparison process is carried out for timber-to-concrete connections using Eurocode 5 part 2 [7] methodology. This paper reports the results of two main series of experimental short-term push-out tests undertaken in the Civil Engineering Laboratory of Minho University, Portugal [8]. 


\section{Eurocode 5 design method}

\subsection{Load-carrying capacity}

The design method for dowel-type fasteners timber connections proposed by Eurocode 5 is based on Johansen's Yield Theory [3], also known as the European Yield Model (EYM). The equations based on this theory predict the load-carrying capacity of a single fastener, per shear plane, loaded perpendicular to his axis, depending on the material properties of the timber and the fasteners and on the geometry of the connection. For the timber and the connector, a rigid-plastic behaviour is assumed. While this assumption considerably simplifies the analysis, it has a small impact on the final results [9]. Figure 1 illustrates the failure modes assumed by EYM for single shear dowel-type timber-to-timber connections. Figures (1-a), (1-b) and (1-c) correspond to failure modes where there is only bearing failure in the timber members by embedment and fasteners behave as rigid elements. Figures (1-d), (1-e) and (1-f) represents the failure modes associated with embedding of the timber members combined with plastic hinge, as a consequence of the lower fastener stiffness. In the same way, Figure 1 shows the failure assumed by EYM for double shear dowel-type timber-to-timber connections. Figures (1-g) and (1-h) correspond to failure modes where there is only bearing failure of the timber member by embedment and fasteners behave as a rigid element and figures, (1-j) and (1-k) show failure modes where the embedment of the timber members is combined with plastic hinges associated with slender fasteners. Based on the stress distribution shown in those figures, and imposing equilibrium, it is possible to quantify the load-carrying capacity associated to each failure mode, (Equation 1) for single shear plane and (Equation 2) for double shear plane. The characteristic value of the load-carrying capacity of the joints, per shear plane and per fastener $\left(F_{v, R k}\right)$, will correspond to the minimum value given by the stress equilibrium and the corresponding failure mode will be the one associated with lower resistance. 


$$
F_{V, R k}=\min \left\{\begin{array}{l}
f_{h, 1, k} t_{1} d \\
f_{h, 2, k} t_{2} d \\
\frac{f_{h, 1, k} t_{1} d}{1+\beta}\left[\sqrt{\beta+2 \beta^{2}\left[1+\frac{t_{2}}{t_{1}}+\left(\frac{t_{2}}{t_{1}}\right)^{2}\right]+\beta^{3}\left(\frac{t_{2}}{t_{1}}\right)^{2}}-\beta\left(1+\frac{t_{2}}{t_{1}}\right)\right]+\frac{F_{a x, R k}}{4} \\
1,05 \frac{f_{h, 1, k} t_{1} d}{2+\beta}\left[\sqrt{\left.2 \beta(1+\beta)+\frac{4 \beta(2+\beta) M_{y, R k}}{f_{h, 1, k} t_{1}^{2} d}-\beta\right]+\frac{F_{a x, R k}}{4}}\right. \\
1,05 \frac{f_{h, 1, k} t_{2} d}{1+2 \beta}\left[\sqrt{2 \beta^{2}(1+\beta)+\frac{4 \beta(1+2 \beta) M_{y, R k}}{f_{h, 1, k} t_{2}^{2} d}}-\beta\right]+\frac{F_{a x, R k}}{4} \\
1,15 \sqrt{\frac{2 \beta}{1+\beta}} \sqrt{2 M_{y, R k} f_{h, 1, k} d+\frac{F_{a x, R k}}{4}} \\
F_{V, R k}=\min \left\{\begin{array}{l}
f_{h, 1, k} t_{1} d \\
0,5 f_{h, 2, k} t_{2} d \\
1,05 \frac{f_{h, 1, k} t_{1} d}{2+\beta}\left[\sqrt{\left.2 \beta(1+\beta)+\frac{4 \beta(2+\beta) M_{y, R k}}{f_{h, 1, k} t_{1}^{2} d}-\beta\right]+\frac{F_{a x, R k}}{4}}\right. \\
1,15 \sqrt{\frac{2 \beta}{1+\beta}} \sqrt{2 M_{y, R k} f_{h, 1, k} d}+\frac{F_{a x, R k}}{4}
\end{array}\right.
\end{array}\right.
$$

where $t_{i}$ is the timber thickness or penetration depth, with $i$ equal to 1 or $2, f_{h, i, k}$ is the characteristic embedding strength in timber member $i, d$ is the fastener diameter, $\beta$ is the ratio between the embedment strength of the members, $M_{y, k}$ is the characteristic fastener yield moment and $F_{a x, R k}$ is the characteristic axial withdrawal capacity of the fastener.

The characteristic values for the embedding strength and the bending capacity of the fastener (yield moment) should be determined according to EN 383:1993 [10] and EN 409:1993 [11] standards, respectively. Nevertheless, the embedding strength for timber based on a large number of embedding tests can be expressed depending on the fastener diameter and the timber density for loads parallel to the grain direction with pre-drilled holes [12]:

$$
f_{h, k}=0,082(1-0.01 d) \rho_{k}
$$

where $\rho_{k}$ is the characteristic timber density, in $\mathrm{kg} / \mathrm{m}^{3}$ and $d$ is the fastener diameter, in $\mathrm{mm}$. 
Blass et al. [13], based on a theoretical derivation of the fastener bending angle at a joint slip of $15 \mathrm{~mm}$, proposed expression for the bending capacity of dowel-type fasteners with a circular (Equation 4) and square (Equation 5) cross section:

$$
\begin{gathered}
M_{y, k}=0,3 f_{u} d^{2,6} \\
M_{y, k}=0,45 f_{u} d^{2,6}
\end{gathered}
$$

where $d$ is the nail diameter as defined in prEN 14592 [14], in mm and $f_{u}$ is the tensile strength of the wire, in $\mathrm{N} / \mathrm{mm}^{2}$.

For the load-carrying capacity of composite timber-concrete connections no particular model or simplified expression is presented by Eurocode 5. If some simplified assumptions could be found in the ENV version, the Eurocode 5 part 2 [7] does not present any equations or model to quantify the load-carrying capacity of dowel-type connections timber-to-concrete.

\subsection{Slip Modulus}

The deformation behaviour of connections with dowel-type fasteners is based on the slip modulus of one single fastener per shear plane. The deformation behaviour should be determined by tests according EN 26891:1991 [5]. The complete load-slip curve achieved in tests, not only provides the ultimate load of the connection, but gives additional information regarding stiffness and ductility.

Nowadays, some derived expressions can be found in the Eurocode 5 part 1 [4] for the slip modulus ( $K_{s}$ in EN 26891:1991 and $K_{s e r}$ in Eurocode 5). For instance, for the case under analysis, connections with dowel-type fasteners using pre-drilled nails, the code proposes that the slip modulus $\left(k_{s e r}\right)$ per shear plane and per fastener, under service load, should be equal to:

$$
K_{\text {ser }}=\rho_{m}{ }^{1,5} \mathrm{~d} / 23
$$

where $\rho_{m}$ is the mean timber density, in $\mathrm{kg} / \mathrm{m}^{3}$ and $d$ is the nail diameter, in $\mathrm{mm}$. 
It has been shown that the mechanical behaviour of the composite structures, such as composite timber-concrete elements, is more often influenced by the joint slip modulus than the joint ultimate load-carrying capacity. In general, it should be stated that strength and stiffness properties of composite timber-concrete connections must be evaluated by tests. Eurocode 5 part 2 [7] contains little information about the behaviour and the design of composite timber-concrete connections. Without the support of experimental results, Eurocode 5 suggests to take into account a value of the slip modulus double than the one of a similar timber-to-timber connection; this seems to be not reasonable. Extensive experimental results, Dias [15], Mascia [16], Gelfi [17] and Soriano [18], disagree with Eurocode 5 suggestion. It is also true that few authors have proposed simplified equations in consequence of the difficulty to evaluate by tests all the parameters involved. However, Turrini [19] and Ceccotti [20] proposed expressions for the determination of the slip modulus based on experimental results that, in some cases, are in good agreement with test results (Figure 2). Both researchers defined the slip modulus in terms of the fastener diameter but, instead of the mean timber density value, both authors suggest the use of the timber modulus of elasticity (Equations 7 and 8).

Turrini:

$$
K_{\text {ser }}=0.08 E d
$$

Ceccotti:

$$
K_{\text {ser }}=0.125 E d
$$

where $E$ is the modulus of elasticity of timber and $d$ is the fastener diameter.

One advantage of the composite timber-concrete slabs in restoration works is the possibility of inserting dowels through the existing wooden planks, thus avoiding their removal. The presence of an interlayer (wooden planks or wood base panel), between timber and concrete and its influence on the behaviour of connection was evaluated 
by Gelfi [21] who proposed the following expression to quantify the connection stiffness:

$$
K_{\text {ser }}=\frac{12 E_{s} I_{s}}{l^{* 3}}
$$

where $E_{s}$ is the timber Young's modulus of timber, $I_{s}$ is the inertia moment of the timber beam, and $l^{*}$ is the ideal length of the fastener given by:

$$
l^{*}=17,3-0,000572 k_{c}-0,00894 k_{w}+0,880 t+4,34 d
$$

where $k_{c}$ is the concrete stiffness, in N/mm ${ }^{2}, k_{w}$ is the timber stiffness, in N/mm ${ }^{2}, t$ is the thickness of the interlayer, in $\mathrm{mm}$, and $d$ is the fastener diameter, in $\mathrm{mm}$.

However it is important to point out that this method presents significant limitations. For example, the range of the fastener diameter should be 12 up $20 \mathrm{~mm}$. For more details see [21]. Ceccotti [6] suggests a rule of thumb of taking the slip modulus of the connection equal to $0.75 K_{\text {ser }}, 0.66 K_{\text {ser }}$ and $0.5 K_{\text {ser }}$ of that corresponding to connection without interlayer, for a gap/ $d$ ratio of 2, 3 and 4 respectively.

Short term tests made according to EN 26891:1991 [5], on specimens that reproduce the good arrangement in the structural element, possibly with only two fasteners in order to avoid an influence of the number of fasteners, are commonly used to achieve the slip modulus and ultimate load.

\section{Experimental assessment of the joint behaviour}

The experimental assessment of load-carrying capacity and deformation properties of timber-to-timber and composite timber-concrete joints should be done according to EN 26891:1991 [5]. This standard sets out the rules and principles for the determination of the load-carrying capacity and deformation properties of timber joints made with mechanical fasteners. However, since there is no specific standard, this one is normally used for composite timber-concrete connections as for timber steel plate connections. 
In this standard all the parameters of the loading procedure are defined based on an initial estimate of the maximum load $\left(F_{\text {est }}\right)$. This estimate is obtained from the experience, from calculations or from results of preliminary tests and is maintained for all the tests, being changed only if, during the tests, the mean value of the maximum load deviates more than $20 \%$ from $F_{\text {est. }}$ The test is performed with load control up to $70 \%$ of the maximum estimated load and, from that point onward, with displacement control. The test ends when the maximum load is reached or when the slip is equal to $15 \mathrm{~mm}$. Note that, in accordance with specifications, the total duration of the test ought to be between a minimum of 10 minutes and a maximum of 15 minutes. In Figure 3 the time-load curve for whole test is shown.

Based on the load-slip curves obtained from the tests, different properties can be calculated including the maximum load $\left(F_{\max }\right)$ and the slip modulus $\left(K_{s}\right)$. The maximum load is obtained directly from the load-slip curve. The slip modulus is computed using Equation 11:

$$
K_{s}=\frac{0,4 F_{\text {est }}}{4 / 3\left(v_{04}-v_{01}\right)}
$$

where $v_{01}$ is the slip measured when $10 \%$ of the estimated load is applied, $v_{04}$ is the slip measured when $40 \%$ of the estimated load is applied $\left(v_{04}\right)$ and $F_{\text {est }}$ is the estimated load.

The slip modulus of the connections is then determined on the basis of the estimated ultimate load and the slip in two points of the load procedure. Nevertheless, it was found by Dias [15] that the method proposed in EN 26891:1991 [5] to determine the joint slip modulus of composite timber-concrete connections may lead to results not completely representative of the actual behaviour of the joints, particularly for joints with pronounced non-linear behaviour in the initial phase, as is the case of joints made with dowel-type fasteners.

\section{Experimental Study}


Push-out tests of timber-to-timber joints in single shear, using round and square nails, and, in double shear using round nails, have been performed. After this, the behaviour of composite timber-concrete joints have been evaluated, using lightweight aggregate concrete taking into account the possibility of using an interlayer between timber and concrete. Table 1 presents the list of the push-out tests realized in the experimental study.

The load-carrying capacity and the deformation behaviour of timber-to-timber joints and composite timber-concrete joints have been determined by tests, according to EN 26891:1991 [5]. However, and for technical reasons, the load procedure suggested by this standard could not be follow. It was impossible to have periods of 30 seconds with constant load and to unload until $10 \%$ of the initial estimate of the maximum load. The stationary periods of loading were removed and a complete unload was carried out, as reported in Figure 4.

During the test, the load and relative displacements (slip deformation) of the joint members were measured. Load was applied with a hydraulic jack and recorded by means of a load cell. To measure the slip deformations two transducers with the accuracy of $\pm 0.1 \mathrm{~mm}$ were used.

For all timber members of the joints, Pinus pinaster Ait. solid timber class E according to the Portuguese Standard NP 4305:1995 [22] was used. Pre-drilling of timber elements up to $60 \%$ of the nail diameter was adopted in all specimens in order to avoid splitting when driving the nails.

\subsection{Single shear timber-to-timber connections}

Two series of tests, composed by three timber members (55 x 55 x $200 \mathrm{~mm})$, made of Pinus pinaster Ait., connected using one nail per side (single shear), were considered. In series $\operatorname{Tr}$ the nails of round cross-section, $3.8 \mathrm{~mm}$ of diameter and length of $100 \mathrm{~mm}$ were used. In series $T s$ square nails with $4.2 \mathrm{~mm}$ side and $100 \mathrm{~mm}$ of length were used. 
Figures 5 and 6 show the specimen arrangement and the test set-up, respectively. The following parameters were obtained from the load-slip response: $\left(F_{\max }\right)$ the maximum load achieved by the joint for a slip no higher than $15 \mathrm{~mm}$; $\left(S_{\max }\right)$ the maximum slip corresponding to $\left(F_{\max }\right)$ (the maximum value allowed is $\left.15 \mathrm{~mm}\right)$; and $\left(K_{s e r}\right)$ the slip modulus, stiffness of the joint for the serviceability states. The slip modulus was determined through two methods: (a) according with EN 26891:1991 expressions (Equation 9) and (b) based on a linear regression analysis of the load-slip response between $0.1 F_{\text {est }}$ and $0.4 F_{\text {est }}$.

Test results in terms of estimate maximum load $\left(F_{\text {est }}\right)$, maximum load $\left(F_{\max }\right)$ and maximum slip $\left(S_{\max }\right)$ for series $\operatorname{Tr}$ are listed in Table 2 . In the same table values for the slip modulus $\left(K_{s e r}\right)$ achieving by the two methods mentioned above are reported.

The results achieved for the maximum load $\left(F_{\max }\right)$ and maximum slip $\left(S_{\max }\right)$ are quite homogeneous, presenting Coefficients of Variation $(\mathrm{CoV})$ less than $10 \%$. On the other hand, the deformation properties present a very large variation (CoV close to $50 \%)$. It is important to point out the existence of a good agreement between the values for the slip modulus $\left(K_{s e r}\right)$ achieved by the regression analysis and according to EN 26891:1991. However, as expected, the regression analysis reaches a lower $\mathrm{CoV}$.

These timber-to-timber connections are very flexible (the maximum load is reached close to the maximum allowed slip) and with a pronounced non-linear behaviour in the initial phase (Figure 7). This non-linear behaviour can give an explanation for the high $\mathrm{CoV}$ values reported for the slip modulus. In fact, the method proposed by EN 26891:1991 for the slip modulus calculation is so sensitive to the experimental data (load, slip) used, that small variations of them result very often in important differences in the slip modulus.

The experimental results for the maximum load, the maximum slip and the slip modulus achieved by series $T s$ are reported in Table 3 . 
The $\mathrm{CoV}$ for the average values of the maximum load and slip are even smaller than those presented for series $T r$. This could be expected, as the variability associated with these two properties decreases with the increase of the stiffness of the nail. The use of regression analysis results in a lower $\mathrm{CoV}$ for the slip modulus, as result of the bigger number of experimental data points (load, slip) used. Moreover the joints present a very flexible behaviour, the average maximum slip value is close to the maximum allowable slip in EN 26891:1991 (15 mm), and a non-linear behaviour since the initial phase is detected (Figure 8).

\subsection{Double shear timber-to-timber connections}

Four specimens of timber-to-timber connections in double shear were tested (series $T d$ ). Round nails with a diameter of $6 \mathrm{~mm}$ and $175 \mathrm{~mm}$ of length, passing through the two interface surfaces, and for that submitted to double shear, were used. In Table 4, results of the maximum experimental values of the load, the slip, the estimated maximum load and the slip calculated by the two methods adopted are present.

The maximum load value show a good homogeneity (CoV equal to $6.26 \%)$ and they are limited by the maximum slip allowed according to EN 26891:1991. From the experimental load-slip curves it can be highlighted a pronounced non-linear behaviour and a constant hardening (Figure 9). Again, the non-linear behaviour detected since the initial phase explains the variability of the slip modulus values achieved according to EN 26891:1991. Based in the regression analysis between the load stages $0.1 F_{\text {est }}$ and $0.4 F_{\text {est }}$ betters results can be reached.

\subsection{Shear tests with timber-concrete connections}

After the experimental studies carried out for timber-to-timber connections reported above, composite timber-concrete were analysed. The same test arrangement used for the experimental study on timber-to-timber connections was used in the analysis of timber-concrete connections. The central timber specimen was kept and the external 
specimens were replaced by concrete members. To assure the connection between timber and concrete, a smooth round nail with $3.4 \mathrm{~mm}$ diameter and length of $70 \mathrm{~mm}$ was used on each side. Lightweight aggregate concrete (LWAC) obtained by mixing expanded clay, natural sand, cement with strength class 42.5 and water was used for the concrete members. Base on tests performed in $(100 \times 100 \times 100 \mathrm{~mm})$ cubes, a characteristic strength for the LWAC of $31.18 \mathrm{~N} / \mathrm{mm}^{2}$, corresponding to the strength class LC20/25 according to prEN 1992-1:2001 [23], was obtained. In order to determine the influence of an interlayer, which can simulate the use of formwork, two test series were used: without interlayer $(C)$ and with interlayer $(\mathrm{Ci})$. In the test the central member was loaded according to EN 26891:1991 [5] and its slip was measured with the transducer used in tests described above. The series arrangements are shown in Figure 10.

These tests were carried out using the procedure already described in the previous section. Table 5 shows the tests results of series $C$.

It must be considered that all the specimens failed with a slip greater than the maximum value imposed by EN 26891:1991. As a consequence, the maximum load $\left(F_{\max }\right)$ corresponds always to the load value for the slip of $15 \mathrm{~mm}$. While the values for the maximum load are quite homogeneous $(\mathrm{CoV}=11 \%)$, the results for the slip modulus $\left(K_{\text {ser }}\right)$ present a CoV greater than $54 \%$.

In Table 6 the experimental results of $C i$ are present.

The experimental results of series $C i$, when compare with the ones of series $C$, show the same homogeneity for the maximum load value $(\mathrm{CoV}=5 \%)$ but a significant reduction of the maximum slip value $(\mathrm{CoV}=27.5 \%)$. With the interposition of an interlayer, with a thickness of $2 \mathrm{~mm}$, between timber and concrete the maximum load value is achieved for a average slip of $9.85 \mathrm{~mm}$. The same variability of the slip modulus values presented by last series exists in series $C i$. The only significant difference is the better reliability 
demonstrated by the regression analysis $(\mathrm{CoV}=46.3 \%$ instead of $66.2 \%$ obtained with EN 26891:1991).

Comparison of the results of tests of series $C$ and $C i$ shows that (Figure 11): (1) the use of an interlayer, with a thickness of $2 \mathrm{~mm}$, between the concrete and the timber increases the load capacity and stiffness; (2) the maximum load in series $C$ is limited by the EN 26891:1991 requirement (15 $\mathrm{mm}$ is the maximum displacement allowed). However in series $C i$ the maximum load is achieved for an average value of $10 \mathrm{~mm}$ for the slip.

\section{Comparison of experimental results with the design method proposed by Eurocode 5}

The load-carrying capacity and slip modulus according to the method proposed in Eurocode 5 for dowel-type fasteners used in timber-to-timber connections and composite timber-concrete connections is compared to the results of the shear tests presented in section 3 .

First, the comparison will focus the load-carrying capacity of the timber-to-timber connections in single and double shear. Table 7 gives the comparison between the experimental results for the maximum load $\left(F_{\max }\right)$ and the failure mode that governs the load-carrying capacity, with the values and modes assumed by the Eurocode 5 . The comparison between the experimental results and the values suggested by the Eurocode 5 is measured through the error term given by:

$$
\operatorname{error}[\%]=\frac{\left|\left(X_{E C 5}-X_{\text {Tests }}\right)\right|}{X_{\text {Tests }}} 100
$$

Where $X_{E C 5}$ and $X_{\text {Tests }}$ are the values suggested by the Eurocode 5 and obtained in the experimental tests, respectively.

It can be concluded that Eurocode 5 predicts accurately dowel-type fasteners load-carrying capacity using Pinus pinaster Ait. solid timber class E. The accuracy decreases if square nails are used (error of $20.9 \%$ instead of $4.0 \%$ for round nails) and 
also for double shear connections (error of $28.3 \%$ ). The failure modes observed in the experimental tests are the ones indicated by Eurocode 5 as conditional (Figure 12).

Unlike the results on load-carrying capacity, the comparison of slip modulus obtained experimentally and using Eurocode 5 shows significant differences (Table 8).

Table 9 shows the comparison between the slip modulus obtained from tests made with composite timber-concrete connections and the corresponding values calculated according to Eurocode 5. It is important to point out that this standard does not propose any method of analysis when an intermediate interlayer is used as permanent formwork. Based on the values shown in Table 9 it can be concluded that a deeper investigation is needed in order to develop more appropriate methods for analyzing the dowel-type fasteners in composite timber-concrete connections. It is necessary that the design method for composite timber-concrete connections foresees the use of permanent formwork as an intermediate interlayer.

\section{Discussion}

In terms of load-carrying capacity of timber-to-timber joints it can be said that the actual version of Eurocode 5 shows good agreement with the experimental results achieved in this work. The EYM (European Yield Model) as always reported good reliability for the dowel-type fasteners load-carrying capacity, in particularly for ductile failure. However, in recent years, researchers had concentrated their attention to improve this theory to some special applications (steel plates, reinforcements) and with the goal of taking into account particular mechanisms like group and rope effects, withdrawal capacity, etc.

The results of the evolution undertaken is shown in Figure 13 where experimental results and values suggested by Eurocode 5 [7] and by the Portuguese National published in1998 [24] are compared.

The main difference is that in the new version of Eurocode 5 the withdrawal capacity of the fastener is considered and so the rope effect is taken into account. Notice that the 
improvements are not so clear as the withdrawal capacity of nails were not determined by tests but by simplified expressions founded in Eurocode 5. The experimental work here reported was carried out previously to the publication of the EN version of Eurocode 5 (Figure 13).

Moreover important modifications have been introduced in the Eurocode 5 for the calculation of the slip modulus. These changes refer to the value of the density of timber that should be considered. In [24] the characteristic value is used, while according to the last version of Eurocode 5 (2004) [4] the mean value of the timber density is needed. In Figure 14 the comparison between experimental results and results according to the Portuguese (1998) and European (2004) versions of Eurocode 5 is illustrated. Based on this comparison it is clear the decrease of accuracy exhibited by the last European version. This is caused by the bigger difference between the characteristic and mean values of the timber species used (Pinus pinaster Ait.), when compared with other species: the average value of the difference is $70 \mathrm{~kg} / \mathrm{m}^{3}$ (EN 338 [25]), while Pinus pinaster Ait. reveals a difference of $125 \mathrm{~kg} / \mathrm{m}^{3}$ (NP 4305 [22]). As a consequence, special attention must be paid when the Portuguese National Standard implementing Eurocode 5 will be prepared.

As it was already mentioned, a more specific analysis methodology of composite timber-concrete connections is needed. Important parameters like the existence of a layer between the two materials or the stiffness of the concrete used must be considered. The actual philosophy of applying coefficients to the EYM developed for timber-totimber joints seems to be inadequate. The experimental results achieved in this work, as the ones reported in ([15], [16], [17] and [18]) prove that need. In addition, authors like Dias [15] show that the test methodology and result analysis proposed by EN 26891:1991 [5] should be reviewed. In Figure 15 the experimental results for the slip modulus achieved in this work for composite timber-concrete connections and the ones proposed by the Eurocode 5 [4] methodology, Turrini [19] (Equation 7) and 
Ceccotti [20] (Equation 8) expressions are reported for comparison. It is clearly showed that a better prediction than that provided by Eurocode 5 could be done. This must not considered a limit of Eurocode 5, since equation (6) was proposed for connections other than timber - concrete ones, and that the suggestion to double the slip modulus found for timber-to-timber connections can be acceptable only for a first roughly approximation; on the contrary equations (7) and (8) were defined for these specific connections on an experimental basis. It is also obvious that, for a correct calibration of equations (7) and (8), a statistically significant number of tests must be done in the future.

\section{Conclusions}

The behaviour of composite timber-concrete structures is governed by the stiffness of the shear connection between timber beam and concrete slab. The actual design method according to Eurocode 5 [4] for those connections is based on modification factors applied to the slip modulus of similar timber-to-timber connections. For the loadcarrying capacity no simplify method is given or suggested, contrary to previous versions.

With the purpose of studying the adequacy of the methodology proposed in the Eurocode 5 for composite timber-concrete connections using the Pinus pinaster Ait. species, experimental test results were compared to the values obtained following the method of Eurocode 5. It was demonstrated that the European Yield Model [3], used in Eurocode 5, is able to predict with reliability the failure mode of the connection. Nevertheless, the results of tests show significantly different values from those obtained using the procedure defined in Eurocode 5.

The experimental results obtained show that a better approximation of the mechanical behaviour can be reached if a different formulation for the slip modulus of timber-to-concrete connections is taking into account. 
In the case of renovating old timber floors and due to economical and architectural reasons it is very often suggested not to change the existing structure and to take the floorboards as permanent formwork: also in this case, a specific analysis is needed and should be introduced in the existing regulation.

\section{References}

[1] Larsen HJ. Introduction: Fasteners, Joints and Composite Structures. In: Thelandersson S, Larsen H J - Timber Engineering. Ed. by Thelandersson S, Larsen HJ, ISBN 0-470-84469-8, 2003.

[2] Mateus TJE. Basis for the design of timber structures. National Laboratory of Civil Engineering (LNEC), Report N. ' 179, Lisbon, 1961, “only available in Portuguese”.

[3] Johansen KW. Theory of Timber Connections, In International Association of Bridge and Structural Engineering, Publ., 9, 1949, 249-262.

[4] EN 1995-1-1:2004. Eurocode 5: Design of Timber Structures - Part 1.1: General Rules and Rules for Buildings. European Committee for Standardization, Brussels, Belgium, (E).

[5] EN 26891:1991. Timber structures - Joints made with mechanical fasteners General principles for the determination of strength and deformation characteristics. ISO 6891-1983 (E).

[6] Ceccotti A. Composite concrete-timber structures. In: Progress in Structural Engineering and Materials, Ed. by Nethercot, D. et al., Vol. 4, N. ${ }^{\circ} 3$, (2002), 264-275.

[7] EN 1995-2:2004. Eurocode 5: Design of Timber Structures - Part 2: Bridges. European Committee for Standardization, Brussels, Belgium, (E).

[8] Branco J. Behaviour of dowel-type fasteners in timber-concrete connections. Master Thesis, Engineering School, University of Minho, Portugal, 2003, 120 p. "only available in Portuguese".

[9] Hilson BO. Joints with dowel-type fasteners - Theory. In: Timber Engineering STEP 1, Basis of Design, Material Properties, Structural Components and Joints. Centrum Hout, The Netherlands, 1995. 
[10] EN 383:1993. Timber structures - Test methods - Determination of embedding strength and foundation values for dowel type fasteners. European Committee for Standardization, Brussels, Belgium, (E).

[11] EN 409:1993. Timber structures - Test methods - Determination of the yield moment for dowel type fasteners - Nails, European Committee for Standardization, Brussels, Belgium, (E).

[12] Whale LRJ, Smith I, Hilson BO. Characteristics properties of nailed and bolted joints under short-term lateral load. Part 4 - The influence of testing mode and fastener diameter upon embedment test data. J. Institute of Wood Science, 11(5), 1989, 156-161.

[13] Blass HJ, Bienhaus A, Krämer V. Effective bending capacity of dowel-type fasteners. Proceedings PRO 22, International RILEM Symposium on Joints in Timber Structures, 2001, pp. 71-80.

[14] prEN 14592:2002. Timber structures - Fasteners - Requirements.

[15] Dias AMPG. Mechanical behaviour of timber-concrete joints. PhD Thesis. 2005. ISBN 90-9019214-X.

[16] Mascia N, Soriano J. Comportamento mecânico de ligações flexíveis em vigas mistas de concreto-madeira, VII EBRAMEM (Madeiras e Estruturas de Madeira), S. Carlos, Brasil, 2000.

[17] Gelfi P, Giuriani E. Stud shear connectors in wood-concrete composite beams. Proc., $1^{\text {st }}$ Int. RILEM Symposium on Timber Engineering, Stockholm, Sweden,13-15 September 1999, RILEM Publications S.A.R.L., 245-254.

[18] Soriano J, Mascia N. Mechanical Behaviour of Flexible Connections in the Timber-Concrete Composite Beams. Joints in Timber Structures. International RILEM. Symposium, Ed. By S. Aicher and H.-W. Reinhardt, Stuttgart, Germany, pp. 291-300.

[19] Turrini G, Piazza M. Una técnica di recupero statico dei solai in legno. Revista técnica. "Recuperare" $n^{\circ}$ 5, 6, 7. 1983.

[20] Ceccotti A. Timber-Concrete Composite Structures, In: Timber Engineering STEP 1, Ed. by Blass, H. J. et al., Lecture E13, 1995.

[21] Gelfi P, Giuriani E. Stud Shear Connection Design for Composite Concrete Slab and Wood Beams. J. Struct. Engrg., Volume 128, Issue 12, pp. 1544-1550, Dec. 2002.

[22] NP 4305:1995. Madeira serrada de Pinheiro bravo para estruturas - classificação visual, LNEC, 1995.

[23] prEN 1992-1:2001. Eurocode 2: Design of Concrete Structures - Part 1-1: General Rules and Rules for Buildings, 1st Draft, 2001.

[24] NP ENV 1995-1-1:1998. Eurocódigo 5 - Projecto de estruturas de Madeira. IPQ, Lisboa. 
[25] EN 338:2004. Structural timber - Strength classes. European Committee for Standardization, Brussels, Belgium, (E). 


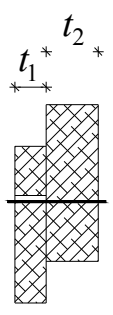

a

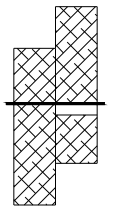

b

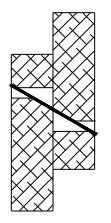

c

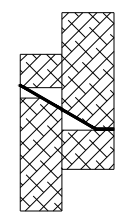

d

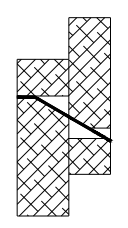

e

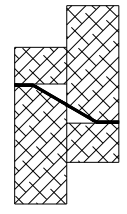

f

Single shear
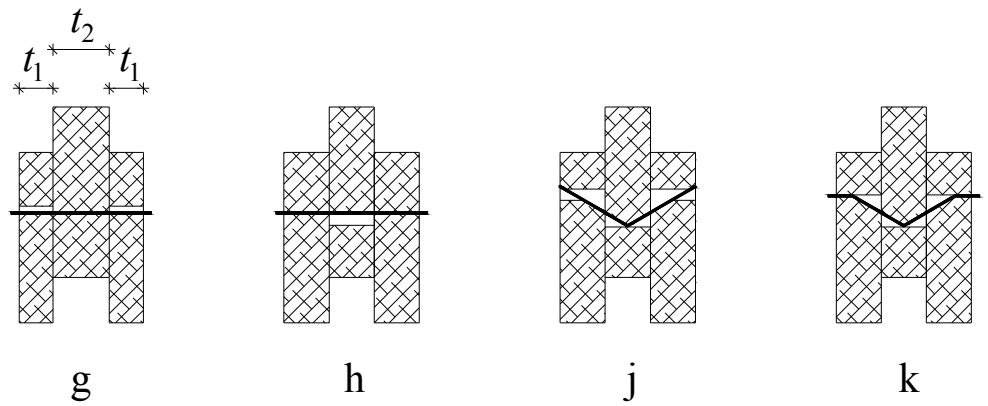

Double shear

Fig. 1. Failure modes assumed by EYM in Eurocode 5, for single and double shear dowel-type timber-to-timber connections. 


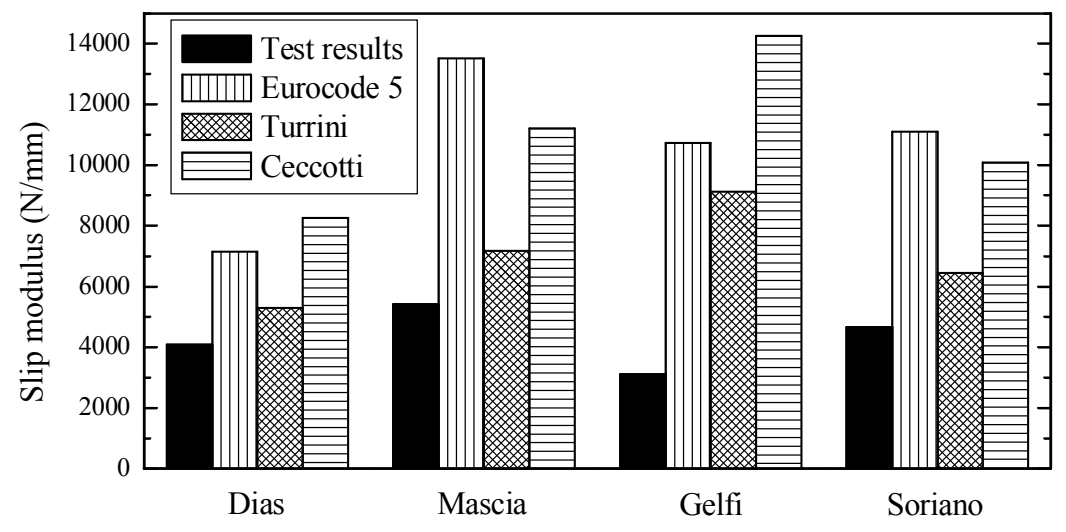

Fig. 2. Comparison of experimental results for the slip modulus and the prediction of Eurocode 5 [4], Turrini [18] and Ceccotti [19]. 


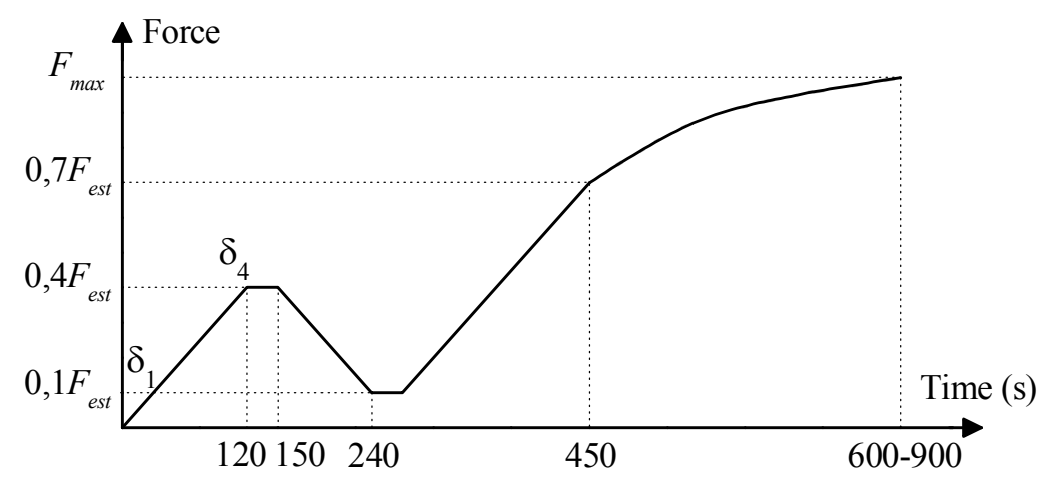

Fig. 3. Load time curve for tests according to EN 26891:1991 [5]. 


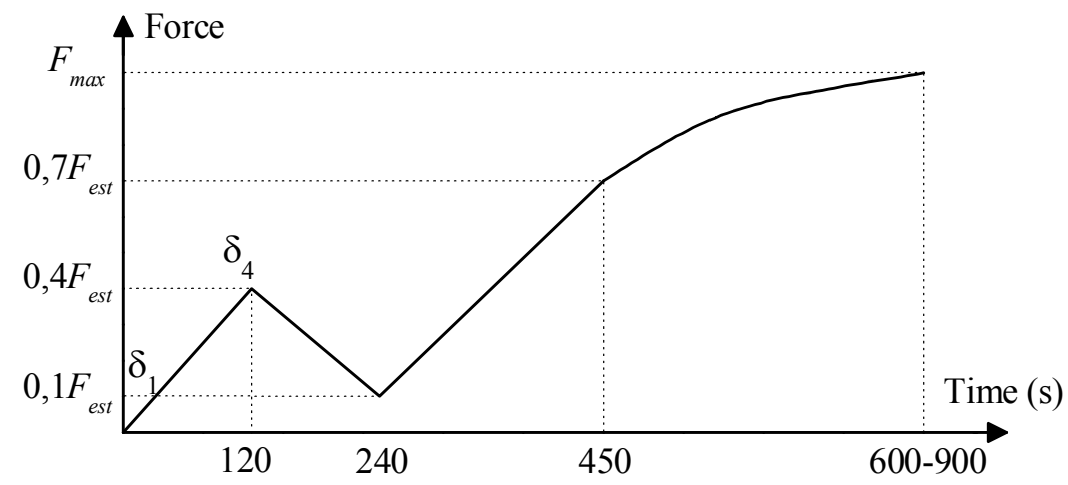

Fig. 4. Load procedure applied in the shear tests. 


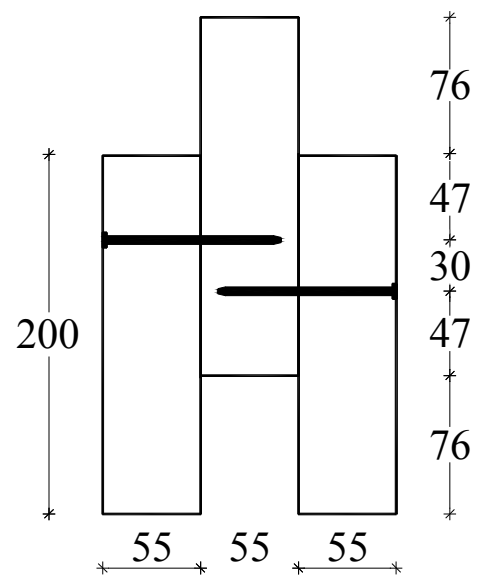

Fig. 5. Joint configuration (dimensions in millimeters). 


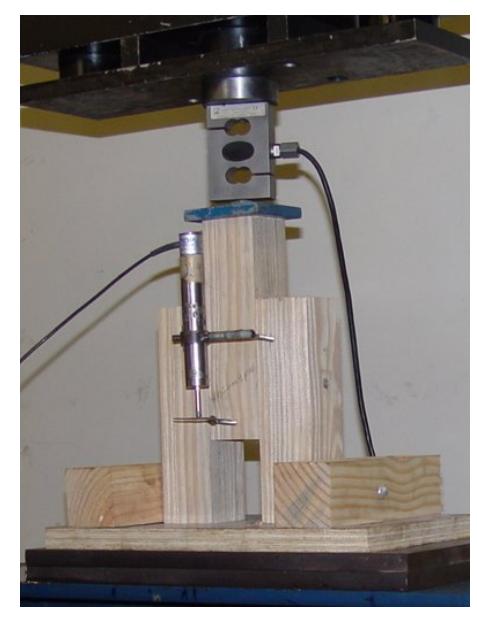

Fig. 6. Test set-up. 

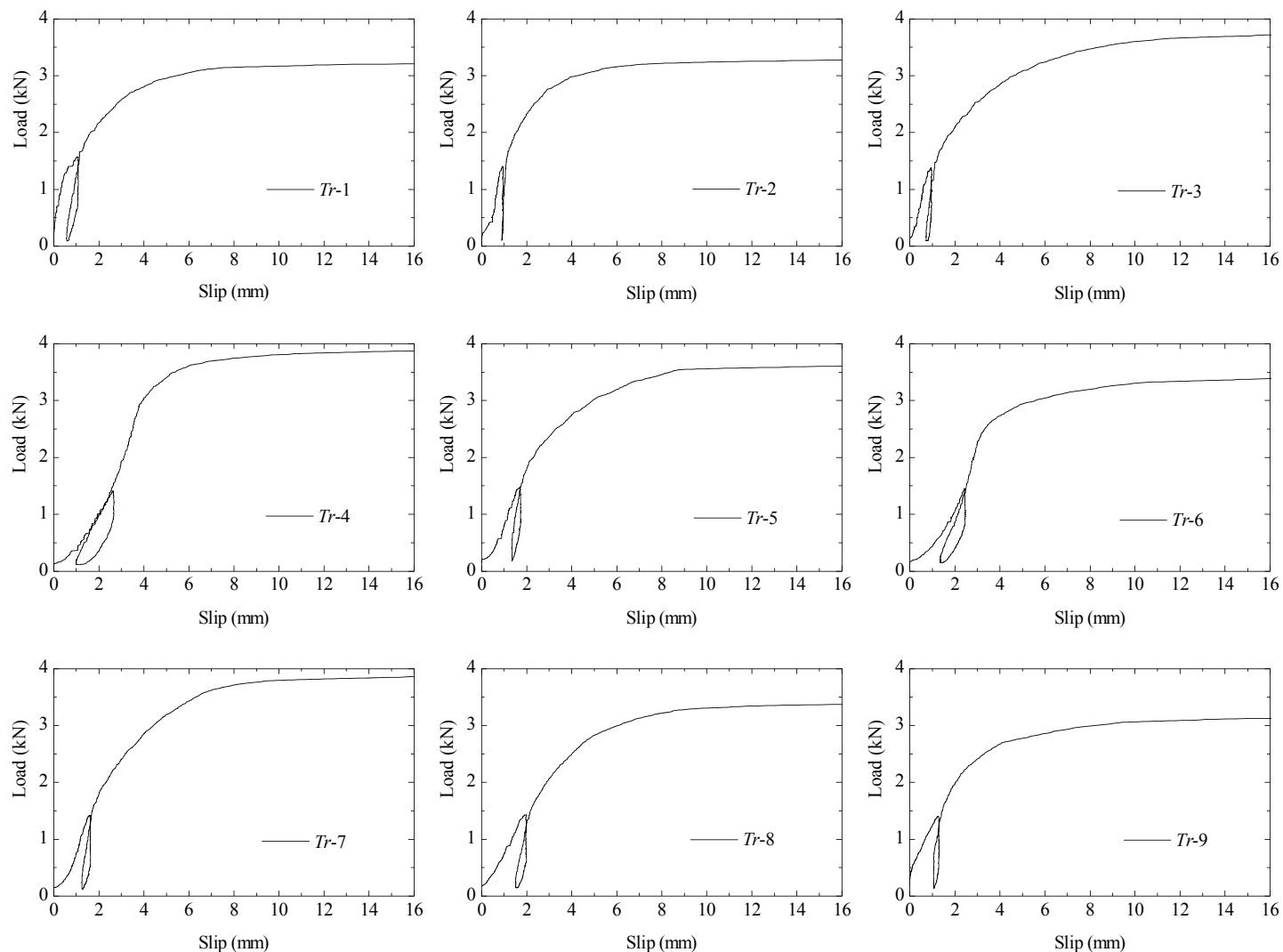

Fig. 7. Load-slip curves for all specimens of the series $T r$. 

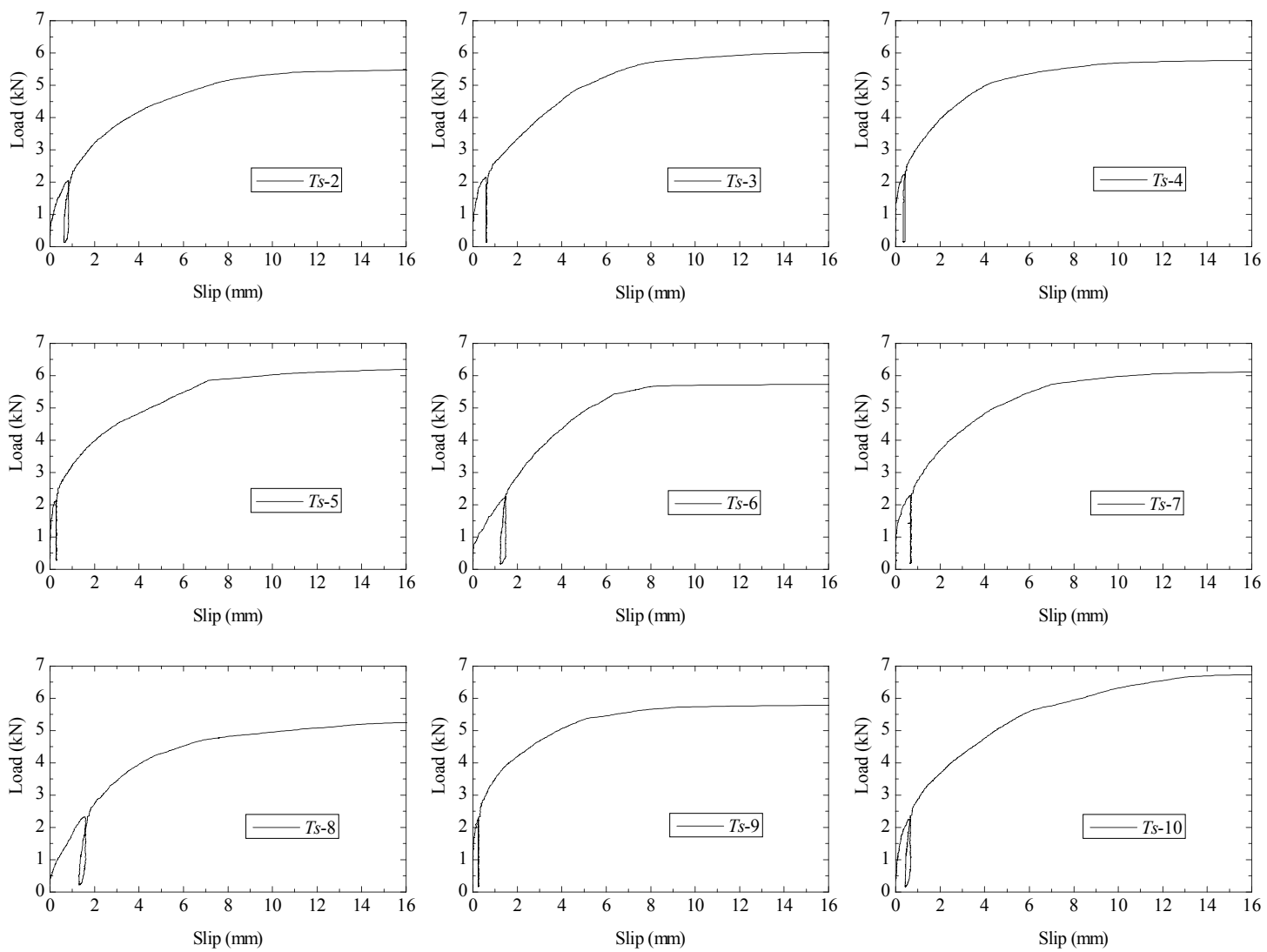

Fig. 8. Load-slip curves for all specimens of the series $T s$. 


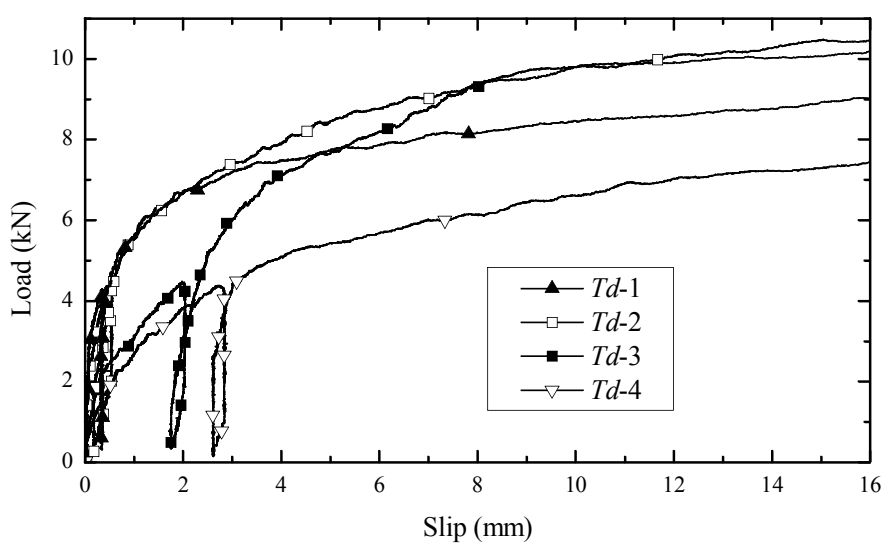

Fig. 9. Load-slip curves of the double shear tests (series $T d$ ). 

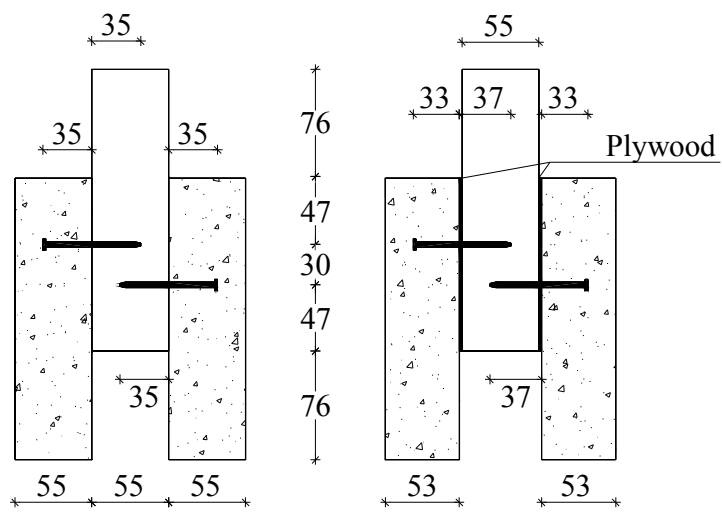

Fig. 10. Composite timber-concrete joint configuration (dimensions in millimeters). 


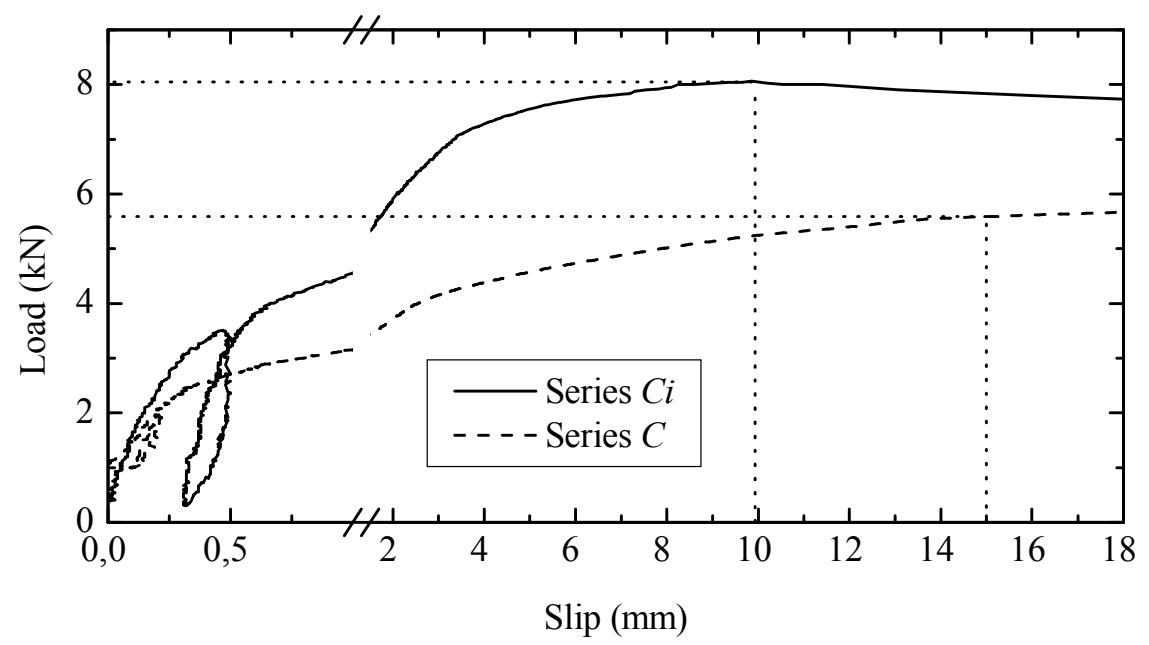

Fig. 11. Comparison between averaging curves obtained in series $C$ and $C i$. 


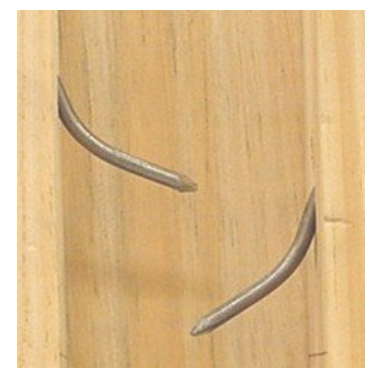

Series $\operatorname{Tr}$

failure mode (f)

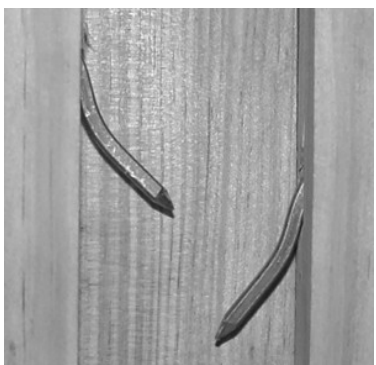

Series $T s$

failure mode (f)

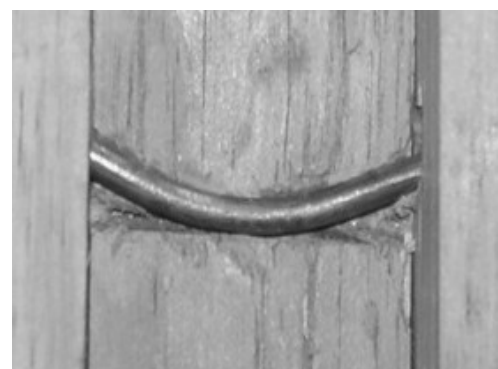

Series $T d$

Fig. 12. Failure modes observed experimentally for timber-to-timber connections. 


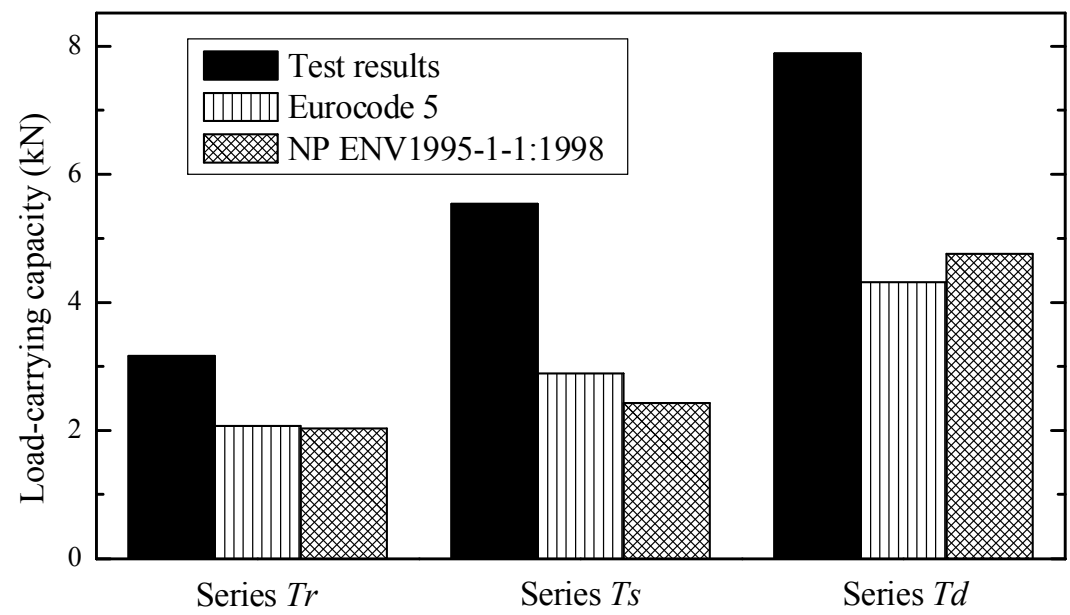

Fig. 13. Loading-carrying capacity: comparison between experimental results and the values proposed by Eurocode 5 and NP EN 1995-1-1:1998. 


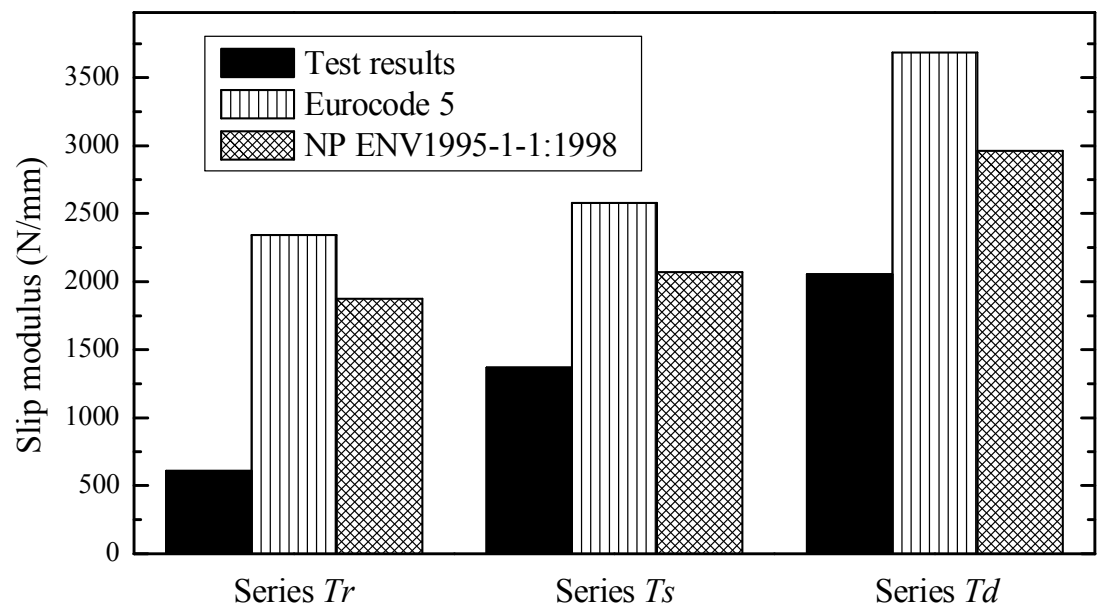

Fig. 14. Slip modulus: comparison between experimental results and the values proposed by Eurocode 5 and NP EN 1995-1-1:1998. 


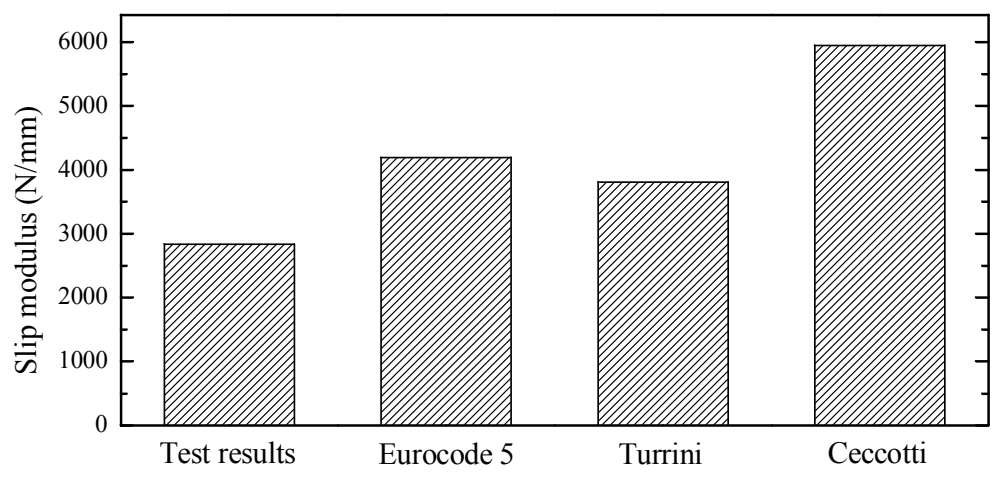

Fig. 15. Slip modulus: comparison between experimental results and the values proposed by different elastic simplified methods. 
Table 1 - Push-out tests realized in the experimental study.

\begin{tabular}{ccccc}
\hline Series & Joint & Shear plane & Fastener & N. of specimens \\
\hline$T r$ & Timber-to-timber & Single & Round nail & 9 \\
$T s$ & Timber-to-timber & Single & Square nail & 10 \\
$T d$ & Timber-to-timber & Double & Round nail & 3 \\
$C$ & $\begin{array}{c}\text { Timber-to-concrete } \\
\text { without interlayer }\end{array}$ & Single & Round nail & 5 \\
& $\begin{array}{c}\text { Timber-to-concrete } \\
\text { with interlayer }\end{array}$ & Single & Round nail & 6 \\
\hline
\end{tabular}


Table 2 - Test results of the single shear timber-to-timber connections using round nails (series $T r$ ).

\begin{tabular}{cccccc}
\hline \multirow{2}{*}{ Test } & $F_{\text {est }}(\mathrm{N})$ & $F_{\max }(\mathrm{N})$ & $S_{\max }(\mathrm{mm})$ & \multicolumn{2}{c}{ Slip modulus $K_{\text {ser }}(\mathrm{N} / \mathrm{mm})$} \\
\cline { 5 - 6 } & & & & EN 26891 & Regression $^{\mathrm{b}}$ \\
\hline a) & 4100 & 3240 & 14.76 & - & - \\
$\operatorname{Tr} 1$ & 3625 & 3300 & 12.44 & 1699 & 2271 \\
$\operatorname{Tr} 2$ & 3650 & 3750 & 15.00 & 1659 & 1604 \\
$\operatorname{Tr} 3$ & 3650 & 3910 & 14.69 & 648 & 650 \\
$\operatorname{Tr} 4$ & 3850 & 3640 & 11.35 & 1004 & 1054 \\
$\operatorname{Tr} 5$ & 3775 & 3440 & 15.00 & 797 & 714 \\
$\operatorname{Tr} 6$ & 3675 & 3900 & 15.00 & 1137 & 1243 \\
$\operatorname{Tr} 7$ & 3725 & 3430 & 13.03 & 745 & 757 \\
$\operatorname{Tr} 8$ & 3775 & 3360 & 14.12 & 2462 & 1864 \\
$\operatorname{Tr} 9$ & 3650 & 3170 & 14.93 & 876 & 819 \\
\hline Average & & 3514 & 14.03 & 1225 & 1220 \\
CoV [\%] & & 7.7 & 9.3 & 48.9 & 47.2 \\
\hline
\end{tabular}

a) Preliminary test for the determination of $F_{\text {est }}$

b) All regression analyses present $r^{2}>0.97$ 
Table 3 - Test results of the single shear timber-to-timber connections using square nails (series $T s$ ).

\begin{tabular}{cccccc}
\hline \multirow{2}{*}{ Test } & $F_{\text {est }}(\mathrm{N})$ & $F_{\max }(\mathrm{N})$ & $S_{\max }(\mathrm{mm})$ & \multicolumn{2}{c}{ Slip modulus $K_{\text {ser }}(\mathrm{N} / \mathrm{mm})$} \\
\cline { 5 - 6 } & & & & EN 26891 & Regression $\left.^{\mathrm{a}}\right)$ \\
\hline$T s 1$ & 5325 & 5540 & 15.00 & 1972 & 1891 \\
$T s 2$ & 5625 & 5950 & 13.98 & 7670 & 3435 \\
$T s 3$ & 5625 & 6060 & 14.63 & 2721 & 2348 \\
$T s 4$ & 5875 & 5810 & 13.55 & 4406 & 2566 \\
$T s 5$ & 5875 & 6330 & 14.72 & 6528 & 5279 \\
$T s 6$ & 5725 & 5750 & 14.81 & 1184 & 1162 \\
$T s 7$ & 5975 & 6180 & 15.00 & 2716 & 2059 \\
$T s 8$ & 6050 & 5270 & 15.00 & 1234 & 1263 \\
$T s 9$ & 5875 & 5840 & 15.00 & 6528 & 4377 \\
$T s 10$ & 5925 & 6780 & 15.00 & 2963 & 3040 \\
\hline Average & & 5951 & 14.67 & 3792 & 2742 \\
CoV [\%] & & 7.08 & 3.44 & 62.17 & 48.23 \\
\hline
\end{tabular}

a) All regression analyses present $r^{2}>0.90$ 
Table 4 - Test results of the double shear timber-to-timber connections (series $T d$ ).

\begin{tabular}{cccccc}
\hline \multirow{2}{*}{ Test } & $F_{\text {est }}(\mathrm{N})$ & $F_{\max }(\mathrm{N})$ & $S_{\max }(\mathrm{mm})$ & \multicolumn{2}{c}{ Slip modulus $K_{\text {ser }}(\mathrm{N} / \mathrm{mm})$} \\
\cline { 5 - 6 } & & & & EN 26891 & Regression $^{\text {a) }}$ \\
\hline a) & 12414 & 9374 & 15.00 & - & - \\
$T d 1$ & 11121 & 10071 & 15.00 & 1685 & 1381 \\
$T d 2$ & 11130 & 10489 & 15.00 & 7259 & 5196 \\
$T d 3$ & 10981 & 9171 & 15.00 & 10295 & 5757 \\
\hline Average & & 9776 & 15.00 & 6413 & 4111 \\
CoV [\%] & & 6.26 & 0.0 & 68.1 & 57.9 \\
\hline
\end{tabular}

a) Preliminary test for the determination of $F_{\text {est }}$

b) All regression analyses present $r^{2}>0.95$ 
Table 5 - Results of the single shear test on timber-to-concrete connections without interlayer (series $C$ ).

\begin{tabular}{cccccc}
\hline \multirow{2}{*}{ Test } & $F_{\text {est }}(\mathrm{N})$ & $F_{\max }(\mathrm{N})$ & $S_{\max }(\mathrm{mm})$ & \multicolumn{2}{c}{ Slip modulus $K_{\text {ser }}(\mathrm{N} / \mathrm{mm})$} \\
\cline { 5 - 6 } & & & & EN 26891 & Regression $^{\text {a }}$ \\
\hline a) & 5372 & 6603 & 15.00 & - & - \\
$C 1$ & 4687 & 5330 & 15.00 & 6392 & 5678 \\
$C 2$ & 5424 & 5082 & 15.00 & 2767 & 2695 \\
$C 3$ & 5424 & 5212 & 15.00 & 3070 & 3417 \\
$C 4$ & 5424 & 6061 & 15.00 & 6509 & 5998 \\
$C 5$ & 5719 & 6179 & 15.00 & 10723 & 10879 \\
\hline Average & & 5745 & 15.00 & 5892 & 5673 \\
CoV [\%] & & 10.8 & 0.0 & 54.8 & 54.4 \\
\hline
\end{tabular}

a) Preliminary test for the determination of $F_{\text {est }}$

b) All regression analyses present $r^{2}>0.90$ 
Table 6 - Results of the single shear test on timber-to-concrete connections with interlayer (series $\mathrm{Ci}$ ).

\begin{tabular}{cccccc}
\hline \multirow{2}{*}{ Test } & \multirow{2}{*}{$F_{\text {est }}(\mathrm{N})$} & $F_{\max }(\mathrm{N})$ & $S_{\max }(\mathrm{mm})$ & \multicolumn{2}{c}{ Slip modulus $K_{\text {ser }}(\mathrm{N} / \mathrm{mm})$} \\
\cline { 5 - 6 } & & & & EN 26891 & Regression $^{\text {a) }}$ \\
\hline Ci1 & 6874 & 7995 & 10.49 & 16435 & 15497 \\
Ci2 & 8225 & 7618 & 7.81 & 6854 & 7266 \\
Ci3 & 8136 & 8408 & 8.41 & 7628 & 7527 \\
Ci4 & 8136 & 7511 & 15.00 & 30512 & 20546 \\
Ci5 & 8136 & 8467 & 8.07 & 20341 & 14379 \\
Ci6 & 8785 & 8372 & 9.34 & 6129 & 7216 \\
\hline Average & & 8062 & 9.85 & 14650 & 12072 \\
CoV [\%] & & 5.2 & 27.5 & 66.2 & 46.3 \\
\hline
\end{tabular}

a) All regression analyses present $r^{2}>0.90$ 
Table 7 - Comparison between the load-carrying experimental results and Eurocode 5.

\begin{tabular}{ccccccc}
\hline \multirow{2}{*}{ Series } & Shear & \multicolumn{3}{c}{ Load-carrying capacity (N) } & \multicolumn{2}{c}{ Failure mode } \\
\cline { 3 - 7 } & plane & Tests & Eurocode 5 & Error (\%) & Tests & EYM \\
\hline$T r$ & \multirow{2}{*}{ Single } & 3514 & 3373 & -4.0 & $(\mathrm{f})$ & $(\mathrm{f})$ \\
$T s$ & & 5951 & 4706 & -20.9 & $(\mathrm{f})$ & $(\mathrm{f})$ \\
$T d$ & Double & 9776 & 7008 & -28.3 & $(\mathrm{k})$ & $(\mathrm{k})$ \\
\hline
\end{tabular}


Table 8 - Comparison between the experimental values for the slip modulus and Eurocode 5 of timber-to-timber connections.

\begin{tabular}{ccccc}
\hline \multirow{2}{*}{ Series } & Shear & \multicolumn{3}{c}{ Slip modulus $K_{\text {ser }}(\mathrm{N} / \mathrm{mm})$} \\
\cline { 3 - 5 } & plane & Tests & Eurocode 5 & Error (\%) \\
\hline$T r$ & \multirow{2}{*}{ Single } & 2341 & 610 & 74 \\
$T s$ & 2579 & 1371 & 47 \\
$T d$ & Double & 3685 & 2056 & 44 \\
\hline
\end{tabular}


Table 9 - Comparison between the experimental values for the slip modulus and Eurocode 5 of composite timber-concrete connections.

\begin{tabular}{ccccc}
\hline \multirow{2}{*}{ Series } & \multirow{2}{*}{ Interlayer } & \multicolumn{3}{c}{ Slip modulus $K_{\text {ser }}(\mathrm{N} / \mathrm{mm})$} \\
\cline { 3 - 5 } & & Tests & Eurocode 5 & Error (\%) \\
\hline$C$ & No & 2837 & 4189 & 48 \\
$C i$ & Yes & 6036 & - & - \\
\hline
\end{tabular}

